\title{
Variation in the biochemical response to L-thyroxine therapy and relationship with peripheral thyroid hormone conversion efficiency
}

\author{
John E M Midgley, Rolf Larisch ${ }^{1}$, Johannes W Dietrich ${ }^{2,3}$ and Rudolf Hoermann ${ }^{1}$ \\ North Lakes Clinical, 20 Wheatley Avenue, Ilkley LS29 8PT, UK \\ ${ }^{1}$ Department of Nuclear Medicine, Klinikum Luedenscheid, Paulmannshoeher Strasse 14 \\ D-58515 Luedenscheid, Germany \\ ${ }^{2}$ Medical Department I, Endocrinology and Diabetology, Bergmannsheil University Hospitals, \\ Ruhr University of Bochum, Buerkle-de-la-Camp-Platz 1, D-44789 Bochum, Germany \\ ${ }^{3}$ Ruhr Center for Rare Diseases (CeSER), Ruhr University of Bochum and Witten/Herdecke University, \\ Alexandrinenstraße 5, D-44791 Bochum, Germany
}

\author{
Correspondence \\ should be addressed \\ to R Hoermann \\ Email \\ rudolf.hoermann@gmail.com
}

\begin{abstract}
Several influences modulate biochemical responses to a weight-adjusted levothyroxine $\left(\mathrm{L}-\mathrm{T}_{4}\right)$ replacement dose. We conducted a secondary analysis of the relationship of $\mathrm{L}_{4} \mathrm{~T}_{4}$ dose to $\mathrm{TSH}$ and free $\mathrm{T}_{3}\left(\mathrm{FT}_{3}\right)$, using a prospective observational study examining the interacting equilibria between thyroid parameters. We studied 353 patients on steady-state $\mathrm{L}_{4}$ replacement for autoimmune thyroiditis or after surgery for malignant or benign thyroid disease. Peripheral deiodinase activity was calculated as a measure of $T_{4}-T_{3}$ conversion efficiency. In euthyroid subjects, the median L- $\mathrm{T}_{4}$ dose was $1.3 \mu \mathrm{g} / \mathrm{kg}$ per day (interquartile range (IQR) $0.94,1.60$ ). The dose was independently associated with gender, age, aetiology and deiodinase activity (all $P<0.001$ ). Comparable $\mathrm{FT}_{3}$ levels required higher $\mathrm{L}-\mathrm{T}_{4}$ doses in the carcinoma group ( $n=143)$, even after adjusting for different TSH levels. Euthyroid athyreotic thyroid carcinoma patients $(n=50)$ received $1.57 \mu \mathrm{g} / \mathrm{kg}$ per day L-T $($ IQR $1.40,1.69)$, compared to $1.19 \mu \mathrm{g} / \mathrm{kg}$ per day $(0.85,1.47)$ in autoimmune thyroiditis $(P<0.01, n=76)$ and $1.08 \mu \mathrm{g} / \mathrm{kg}$ per day $(0.82,1.44)$ in patients operated on for benign disease $(P<0.01, n=80)$. Stratifying patients by deiodinase activity categories of $<23,23-29$ and $>29 \mathrm{nmol} / \mathrm{s}$ revealed an increasing $\mathrm{FT}_{3}-\mathrm{FT}_{4}$ dissociation; the poorest converters showed the lowest $\mathrm{FT}_{3}$ levels in spite of the highest dose and circulating $\mathrm{FT}_{4}(P<0.001)$. An $\mathrm{L}_{4} \mathrm{~T}_{4}$-related $\mathrm{FT}_{3}-\mathrm{TSH}$ disjoint was also apparent; some patients with fully suppressed TSH failed to raise $\mathrm{FT}_{3}$ above the median level. These findings imply that thyroid hormone conversion efficiency is an important modulator of the biochemical response to $\mathrm{L}_{4} ; \mathrm{FT}_{3}$ measurement may be an additional treatment target; and $\mathrm{L}-\mathrm{T}_{4}$ dose escalation may have limited success to raise $\mathrm{FT}_{3}$ appropriately in some cases.
\end{abstract}

\author{
Key Words \\ - thyroid hormone \\ replacement \\ - L-T4 therapy \\ - levothyroxine \\ - TSH \\ - triiodothyronine \\ - deiodinase \\ - conversion
}

\section{Introduction}

Thyroid disorders are among the most prevalent diseases in the western world, affecting as many as one out of seven adults (1). They are frequently associated with overt thyroid dysfunction, particularly various degrees of hypothyroidism that require thyroid hormone replacement $(2,3)$. This is mainly done by administration of

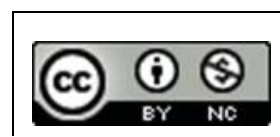

This work is licensed under a Creative Commons Attribution-NonCommercial 4.0 International License. 
synthetic levothyroxine ( $\left.\mathrm{L}_{-} \mathrm{T}_{4}\right)$, which is a well-established, convenient, safe and inexpensive treatment modality $(4,5)$. However, this does not accurately reflect the natural direct secretion pattern of both thyroid hormones triiodothyronine $\left(\mathrm{T}_{3}\right)$ and thyroxine $\left(\mathrm{T}_{4}\right)$ by the thyroid gland $(6,7)$. Unlike other drugs, dosing of $\mathrm{L}^{-} \mathrm{T}_{4}$ is not fixed but has to be titrated according to individual needs. Dose adequacy is mainly defined by reference to suitable biochemical standards, particularly thyrotropin (TSH) (8). This parameter has evolved into the main treatment target to be monitored and kept within an assumed euthyroid range (9). A number of studies have attempted to predict $\mathrm{T}_{4}$ requirement, and various regimes for a starting dose have been proposed based on an average of $1.6 \mu \mathrm{g} / \mathrm{kg}$ body weight (BW) or by more refined weight- or BMI-related algorithms (10, 11, $12,13,14,15,16)$.

Although TSH measurement has dominated procedural management of thyroid replacement by its apparent ease and good standardisation, a disturbingly high proportion of patients remains unsatisfied with the treatment they receive $(17,18)$. This has prompted some authors including our group to question the validity of relying on the TSH level as the sole measure of dose adequacy in $\mathrm{L}^{-} \mathrm{T}_{4}$-treated patients $(19,20,21)$. We have shown that the homeostatic equilibria between TSH and peripheral thyroid hormones are modulated by various influences such as age, body mass and the treatment modality itself (22). As a controlling element, the effective TSH level derived in a healthy normal population cannot necessarily be inferred to be equally optimal for a given patient on $\mathrm{L}^{-\mathrm{T}_{4}}$ medication, because the constitutive equilibria between TSH and thyroid hormones, especially $\mathrm{FT}_{3}$, differ in health and disease (22).

In the present analysis, we examined the relationship of the $\mathrm{L}_{-} \mathrm{T}_{4}$ dose with clinical categories and biochemical outcomes such as $\mathrm{TSH}, \mathrm{FT}_{4}$ and $\mathrm{FT}_{3}$ levels. We sought to define the interaction between TSH and the $\mathrm{FT}_{3}$ target and also to analyse the influences of modulators such as gender, age, disease category or the efficiency of $\mathrm{T}_{3}$ conversion from $\mathrm{T}_{4}$.

\section{Subjects and methods}

\section{Study design and objective}

An open prospective observational study (ClinicalTrials.gov NCT01969552) was conducted at the Department of Nuclear Medicine at Klinikum Luedenscheid, Germany, between July 2013 and February 2014 and approved by the Ethics Committee of the University of Muenster, Germany. Participants gave written informed consent.

The present secondary analysis is restricted to the subgroup of patients on steady $\mathrm{L}_{-} \mathrm{T}_{4}$ treatment, examining dose requirements of $\mathrm{L}^{-} \mathrm{T}_{4}$ including conditioning modulators, thyroid hormone conversion efficiency and relationships with biochemical outcomes such as TSH, $\mathrm{FT}_{4}$ and $\mathrm{FT}_{3}$ levels. The primary study outcome, namely the analysis of the interacting equilibria and interrelations between thyroid parameters under various conditioning influences such as gender, age and body mass and $\mathrm{L}^{-\mathrm{T}_{4}}$ treatment has already been reported (22).

\section{Patients}

The original study involved 1912 adult patients who were consecutively seen, were free of severe comorbidity and provided written informed consent. For this subgroup analysis, 353 patients on thyroid hormone replacement meeting the following criteria were included: being seen as outpatients, presenting in a controlled functional state $\left(\mathrm{FT}_{4} \geq 10 \mathrm{pmol} / \mathrm{l}\right.$ and $\left.\mathrm{TSH} \leq 4 \mathrm{mU} / \mathrm{l}\right)$ and having reached a steady state on a constant $\mathrm{L}_{-} \mathrm{T}_{4}$ medication. Although infrequently seen in an ambulatory setting, patients with severe non-thyroidal illness or potentially interfering comorbidities were ineligible to participate in the study. This exclusion extended to other conditions and the use of comedications that may interfere with the resorption or measurement of thyroid hormones or with pituitary TSH. Patients with $\mathrm{T}_{3} / \mathrm{T}_{4}$ combination therapy $(n=9)$, anti-thyroid drug use $(n=99)$, hypothalamic/pituitary diseases $(n=5)$ or pregnancy $(n=3)$ were excluded before analysis.

Diagnostic procedures included a detailed history, physical examination, standardised questionnaire documenting gender, age, height, weight, smoking habits (75\% answered), prior surgery or radioiodine treatment, thyroid medication (brand, dosage, duration, time of intake), other drugs, laboratory tests $\left(\mathrm{FT}_{3}, \mathrm{FT}_{4}, \mathrm{TSH}\right.$ and, if autoimmune thyroiditis was suspected or to be excluded, thyroid peroxidase antibodies (TPO-Ab) or TSH-receptor antibodies (TSH-R Ab)) and thyroid imaging.

\section{Laboratory methods}

$\mathrm{TSH}, \mathrm{FT}_{3}$ and $\mathrm{FT}_{4}$ were measured with an automated direct chemoluminescence method (Advia Centaur XP, Siemens Healthcare Diagnostics, Erlangen, Germany). TSH is traceable to the 3rd International Standard for TSH (WHO, IRP 
81/565). A TSH range from 0.006 to $160 \mathrm{mU} / \mathrm{l}$ was linear, and coefficient of variations of inter-assay imprecision ranged from $0.9 \%$ to $2.4 \%$. Reference intervals were laboratory established and pre-evaluated for the local population, using 10-23 pmol/1 for $\mathrm{FT}_{4}, 3.1-6.8 \mathrm{pmol} / \mathrm{l}$ for $\mathrm{FT}_{3}$ and $0.4-4.0 \mathrm{mU} / \mathrm{l}$ for TSH (23).

TPO-Abs were determined by a competitive chemoluminescence method (ADVIA Centaur XP, Siemens Healthcare Diagnostics, reference range $<60 \mathrm{U} / \mathrm{ml}$ ) and TSH-R Abs by competitive ELISA (Euroimmun AG, Lübeck, Germany, reference range $<2 \mathrm{U} / \mathrm{l})$.

\section{$\mathrm{FT}_{3}-\mathrm{FT}_{4}$ ratio and calculated deiodinase activity}

As measures of conversion efficiency, we calculated the $\mathrm{FT}_{3}-\mathrm{FT}_{4}$ ratio by simple division of both parameters in pmol/l and the sum activity of peripheral deiodinases (SPINA-GD, termed 'deiodinase activity,' thereafter, $\mathrm{nmol} / \mathrm{s}$ ) from equilibrium levels of $\mathrm{FT}_{4}, \mathrm{FT}_{3}$ and estimated constant parameters for plasma protein binding, distribution and elimination with

$\hat{G}_{D}=\frac{\beta_{31}\left(K_{M 1}+\left(\mathrm{FT}_{4}\right)\right)\left(1+K_{30}(\mathrm{TBG})\right)\left(\mathrm{FT}_{3}\right)}{\alpha_{31}\left(\mathrm{FT}_{4}\right)} \mathrm{nmol} / \mathrm{s}$

as previously described $(20,21,24)$.

Although the two measures are closely related in the linear part of the substrate relationship defined by Michaelis-Menten kinetics, only the more complex formula $\left(G_{D}\right)$ accounts for the saturation kinetics of the enzyme.

In addition to using estimated deiodinase activity as a continuous variable, we divided deiodinase activity in three distinct categories defining poor $(<23 \mathrm{nmol} / \mathrm{s})$, intermediate $(23-29 \mathrm{nmol} / \mathrm{s})$ or good ( $>29 \mathrm{nmol} / \mathrm{s})$ converters. The cut-offs were pre-specified based on observations in $\mathrm{L}_{-} \mathrm{T}_{4}$-treated patients vs healthy untreated subjects and in low $(<5 \mathrm{ml})$ vs higher thyroid volumes (22). They approximate turning points in the relationship between deiodinase activity and $\mathrm{FT}_{3}$, defining a central region with a derivative of about 0 and low or high regions with steeper slopes.

\section{Thyroid ultrasound and scintigraphy}

Thyroid volume was sonographically (10 MHz transducer) determined according to the ellipsoid formula. Reference values were $<18 \mathrm{ml}$ for females and $<25 \mathrm{ml}$ for males. A volume $<1 \mathrm{ml}$ was considered athyreotic. Larger nodules were further examined by scintigraphy.

\section{Statistical methods}

Descriptive data are reported as median plus interquartile range (IQR). We used Wilcoxon's rank sum or a $\chi^{2}$ test in case of categorical variables for comparison of baseline characteristics. Correlations are based on Pearson's product-moment when suitable or Kendall's $\tau$. Multiple variables and conditional influences were analysed by a generalised linear model (GLM) and approximated by a linear regression function over restricted intervals. $\beta$ coefficients were derived from a linear model. TSH was used after logarithmic transformation. We tested for collinearity in the models using the variance inflation factor. A GLM with a binomial function (logistic regression) was used to assess success rates of the ${\mathrm{L}-\mathrm{T}_{4}}_{4}$ dose for reaching a TSH or $\mathrm{FT}_{3}$ target and to create doserelated probability plots. Relative proportions were statistically compared by receiver operating characteristic curves and Delong's test. $P$ values $<0.05$ were considered significant for all tests. Statistical analyses were performed using Deducer (version 0.7-7) and the R statistical package (Mac version 3.1.2) $(25,26)$.

\section{Results}

The present analysis comprises 353 patients in a stable controlled non-hypothyroid state on thyroid hormone replacement with $\mathrm{L}_{-} \mathrm{T}_{4}$. Patient characteristics are shown in Table 1. Of the total study group, 304 patients were euthyroid according to $\mathrm{FT}_{4}, 342$ according to $\mathrm{FT}_{3}$ and 216 according to $\mathrm{TSH}$, based on their respective reference intervals with all displaying clinically satisfactory levels of medication.

Dose requirements associated with biochemical euthyroidism $(n=208)$ defined by the reference ranges of all three parameters varied widely from 25 to $275 \mu \mathrm{g}$ /day $\mathrm{L}-\mathrm{T}_{4}$ (mean 98, median 100 (IQR 75, 125)) or 0.3 to $2.2 \mu \mathrm{g} / \mathrm{kg}$ BW per day (mean 1.2, median 1.3 (IQR 0.94, 1.60)). In univariate linear models, the $\mathrm{L}^{-\mathrm{T}_{4}}$ dose in the treated euthyroid panel was significantly associated with gender, age, body mass index, aetiology of disease, $\mathrm{T}_{3}-\mathrm{T}_{4}$ ratio and calculated deiodinase activity (all $P<0.001$ ) but not with TSH $(P=0.94)$. The influences remained independently predictive in a multivariable model (Table 2 ).

TSH levels in the euthyroid range were unrelated to any of the above influences except disease category $(P=0.003)$, as might be expected considering the lower TSH target in malignant disease. Deiodinase activity was positively associated with thyroid volume $(\tau=0.23$,

This work is licensed under a Creative Commons Attribution-NonCommercial 4.0 International License. 
Table 1 Characteristics of study group $(n=353)$. For referencing purpose, parameters in 146 disease-free individuals from the same study were as follows: median age $38(26,49)$ years, TSH $1.62(1.12,2.25) \mathrm{mU} / \mathrm{l}, \mathrm{FT}_{3} 5.0(4.8,5.2) \mathrm{pmol} / \mathrm{l}, \mathrm{FT}_{4}$ 14.0 (13.0,15.1) pmol/l, calculated deiodinase activity $32.8(30.0,36.2) \mathrm{nmol} / \mathrm{s}$, thyroid volume $10(8,13) \mathrm{ml}(22)$.

\section{Parameter \\ Gender (female, male) \\ Age (years) \\ In women vs men \\ Disease aetiology (\%)}

Surgery, radioiodine treatment (\%)

BMI $\left(\mathrm{kg} / \mathrm{m}^{2}\right)$

Dose ( $\mu \mathrm{g} / \mathrm{day})$

Weight-adjusted daily dose ( $\mu \mathrm{g} / \mathrm{kg}$ per day)

$\mathrm{TSH}(\mathrm{mU} / \mathrm{l})$

$\mathrm{FT}_{3}(\mathrm{pmol} / \mathrm{l})$

$\mathrm{FT}_{4}(\mathrm{pmol} / \mathrm{l})$

TPO-Ab (U/l)

$\mathrm{FT}_{3}-\mathrm{FT}_{4}$ ratio

Deiodinase activity (nmol/s)

Thyroid volume (ml) - total group

Autoimmune thyroiditis

Benign thyroid disease post surgery

Thyroid carcinomab

\section{Median (IQR) or percentage}

$280(79 \%), 73(21 \%)$

$56(46,66)$

$53(45,66)$ vs $59(53,64), P=0.03$

Autoimmune thyroiditis $27 \%$

Benign thyroid disease after surgery $32 \%$

Thyroid carcinoma ${ }^{a} 41 \%$

$73 \%, 42 \%$

$27.5(24.1,30.8)$

$100(75,150)$

$1.47(1.09,1.72)$

$0.64(0.12,1.47)$

$4.80(4.40,5.30)$

$18.6(16.2,21.1)$

$450(48,1300)$, positive $65 \%, n=97$

$0.26(0.24,0.29)$

$24.3(21.8,27.1)$

$2(0,7)$

$7(4,11)$

$6(2,10)$

$0(0,0)$

${ }^{a} 82 \%$ of the thyroid carcinoma patients had a higher TNM stage than 1.

${ }^{b} 96 \%$ had no detectable residual thyroid volume by ultrasound after total thyroidectomy and radioiodine treatment.

$P<0.001, n=208)$ but inversely correlated with weightadjusted $\mathrm{L}_{\mathrm{T}} \mathrm{T}_{4}$ dose $(r=-0.37, P<0.001, n=208)$.

In a biochemically defined euthyroid state excluding subclinically hyperthyroid subjects, athyreotic thyroid carcinoma patients received significantly higher doses of $\mathrm{L}^{-\mathrm{T}_{4}}(1.57 \mu \mathrm{g} / \mathrm{kg}$ BW per day (IQR $\left.\left.1.40,1.69), n=50\right)\right)$ than patients with autoimmune thyroiditis $(1.19 \mu \mathrm{g} / \mathrm{kg}$ BW per day (IQR $0.85,1.47), n=76, P<0.001)$ ) or benign thyroid disease post surgery $(1.08 \mu \mathrm{g} / \mathrm{kg}$ BW per day (IQR 0.82, 1.44), $n=80, P<0.001)$ ). Furthermore, after adjusting for differing levels of TSH suppression in a linear model the weight-adjusted $\mathrm{L}^{-\mathrm{T}_{4}}$ dose was higher in athyreotic carcinoma patients compared to autoimmune thyroiditis or benign disease $(P<0.001$, Fig. 1A). Similarly, the dose required to achieve the same $\mathrm{FT}_{3}$ concentration was higher in the carcinoma group $(P<0.001$, Fig. 1B).

Median thyroid volume was $0 \mathrm{ml}$ (IQR $0,0 \mathrm{ml}$ ) in carcinomas, $7 \mathrm{ml}$ (IQR 4, $11 \mathrm{ml}$ ) in autoimmune thyroiditis and $6 \mathrm{ml}$ (IQR 3,8 $\mathrm{ml}$ ) in benign goitre post surgery. The weight-adjusted $\mathrm{L}_{-} \mathrm{T}_{4}$ dose was inversely correlated with the thyroid volume in the three diagnostic groups $(r=-0.22, P=0.002, n=208)$.

Three distinct categories of conversion efficiency were defined (see Subjects and methods) as follows: poor converters $<23 \mathrm{nmol} / \mathrm{s}$, intermediate converters

23-29 nmol/s and good converters $>29 \mathrm{nmol} / \mathrm{s}$ deiodinase activity. The poor converters reached significantly $(P<0.001)$ higher $\mathrm{FT}_{4}$ concentrations in the circulation than intermediate or good converters but, at the same time, showed significantly $(P<0.001)$ lower absolute $\mathrm{FT}_{3}$ levels compared to the other two groups (Fig. 2). While the $\mathrm{FT}_{3}-\mathrm{FT}_{4}$ dissociation was apparent in all three disease entities, it was most pronounced in the carcinoma group ( $n=143$, Fig. 2). The latter group showed the highest

Table $2 \beta$ coefficients in a linear model of covariates predicting dose of $\mathrm{L}_{4} \mathrm{~T}_{4}$ in the euthyroid panel. The multivariable model was simultaneously fitted with the parameters listed, all of which were significant predictors of the $L-T_{4}$ dose in univariate models. All variance inflations factors were $<1.2$.

\section{Variable}

Gender male vs female

Disease aetiology

Autoimmune vs

malignant disease

Benign goitre vs malignant disease

Age

BMI

Deiodinase activity

\begin{tabular}{c}
$\boldsymbol{\beta}$ coefficient $(95 \% \mathrm{Cl})$ \\
\hline $0.22(0.11,0.33), P<0.001$ \\
$-0.33(-0.47,-0.19), P<0.001$ \\
$-0.34(-0.48,-0.20), P<0.001$ \\
$-0.26(-0.37,-0.15), P<0.001$ \\
$0.33(0.22,0.44), P<0.001$ \\
$-0.27(-0.39,-0.15), P<0.001$ \\
\hline
\end{tabular}




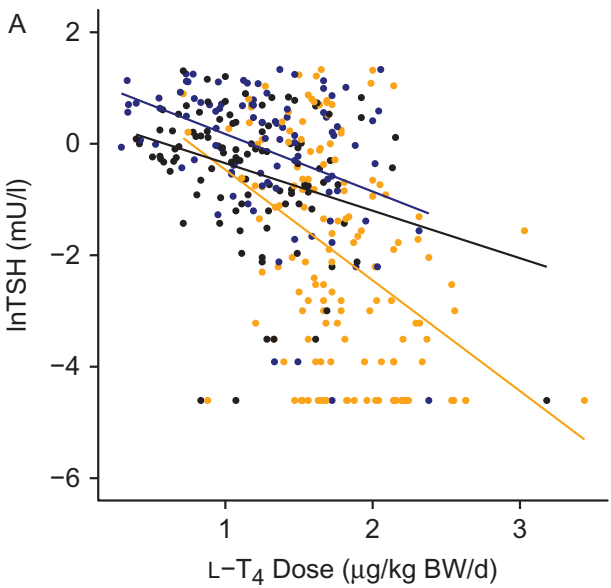

Disease

$\rightarrow$ Carcinoma

$\rightarrow$ AIT

$\rightarrow$ Goitre

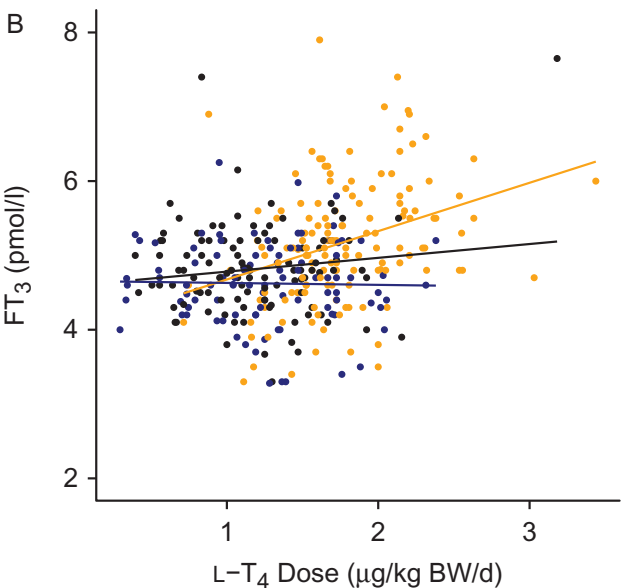

Disease

- Carcinoma

$\rightarrow$ AIT

$\rightarrow$ Goitre

Figure 1

$\mathrm{TSH}(\mathrm{A})$ or $\mathrm{FT}_{3}$ (B) vs weight-adjusted $\mathrm{L}-\mathrm{T}_{4}$ dose in three groups of patients on thyroid hormone replacement, with autoimmune thyroiditis $(n=96)$, after surgery for benign goitre $(n=111)$ or thyroid carcinoma $(n=143)$. Between group differences in both panels were significant $(P<0.01)$ and remained so after adjusting for volume (not shown, $P<0.01$ ), as evidenced by linear models with the diagnostic group as a covariate. See text for further details. AIT, autoimmune thyroiditis; Goitre, goitre post surgery for benign nodular thyroid disease.

proportion of poor converters (Fig. 2). The converter groups were similar $(P>0.1)$ in their age, BMI, weightadjusted $\mathrm{L}_{-} \mathrm{T}_{4}$ dose and TSH levels except for men being overrepresented in the good converter group $(P<0.01)$. Converter categories of the carcinoma group were comparable $(P=0.42)$ in their thyroid residual volumes, which were below $1 \mathrm{ml}$ in $96 \%$ of all cases. In contrast, in the combined group of benign diseases the converter status was significantly associated with thyroid volume $(4(2,8)$ vs $7(4,11)$ vs $8(5,12) \mathrm{ml}, P=0.009)$. Thyroid volumes differed between the carcinoma group and the benign diseases $(P<0.001)$ but not between autoimmune thyroiditis and goitre post surgery $(P=0.25$, Table 1$)$.
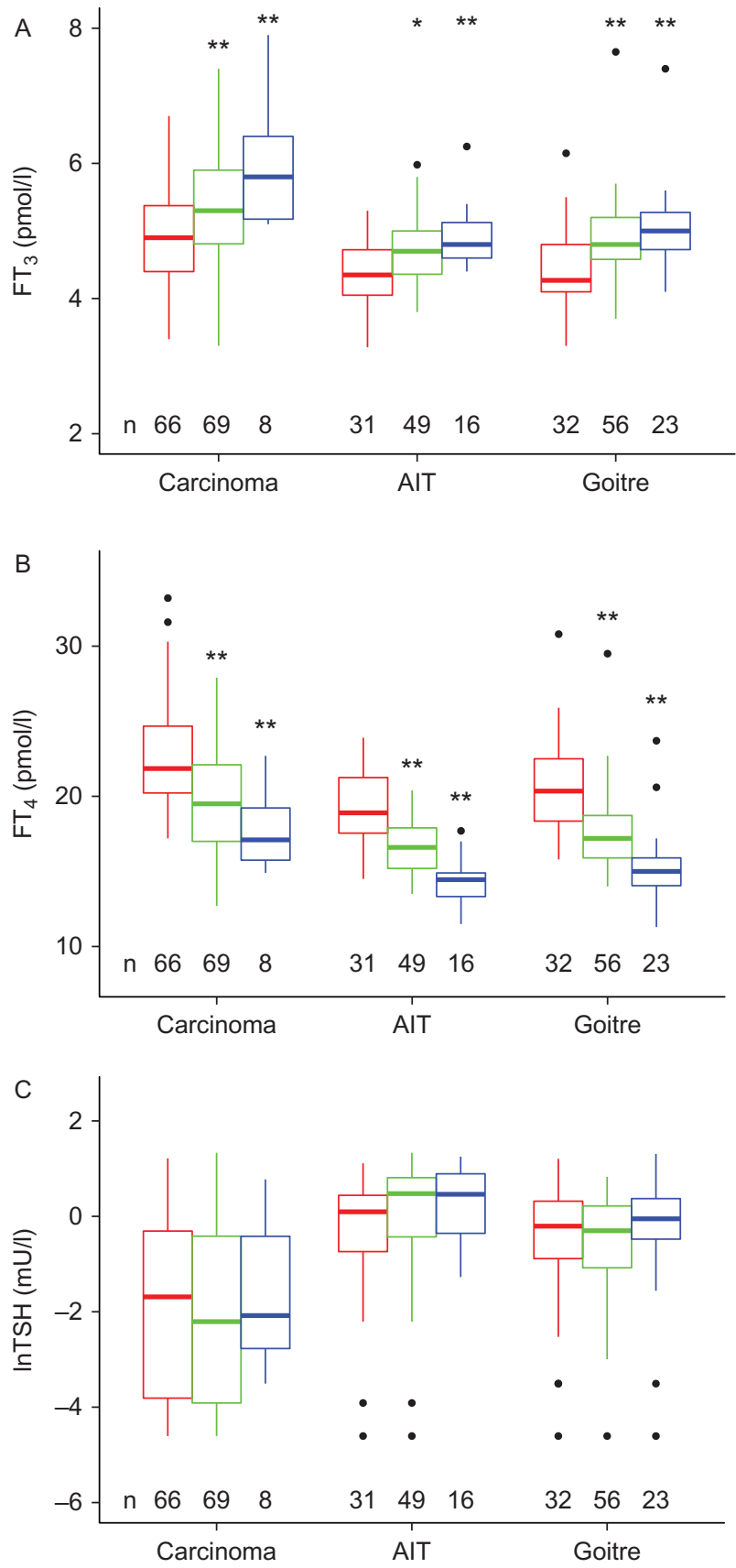

Figure 2

$\mathrm{FT}_{3}(\mathrm{~A}), \mathrm{FT}_{4}(\mathrm{~B})$ and TSH (C) levels in $\mathrm{L}_{4}$-treated patients stratified by disease and conversion efficiency. The disease entities were closely associated with categories of the thyroid volume (see Table 1 and text). The red box refers to poor converters (calculated deiodinase activity $<23 \mathrm{nmol} / \mathrm{s}$ ), green to intermediate converters (deiodinase activity 23-29 nmol/s) and blue to good converters (deiodinase activity $>29 \mathrm{nmol} / \mathrm{s}$ ). Remarkably, absolute $\mathrm{FT}_{3}$ concentrations were lowest in the poor converter group in all disease categories, while $\mathrm{FT}_{4}$ levels were highest in the poor converters. Wilcoxon test, revealed significant differences compared to each first group; ${ }^{*} P<0.05, * * P<0.001$.

AIT, autoimmune thyroiditis; goitre, goitre post surgery for benign nodular thyroid disease.

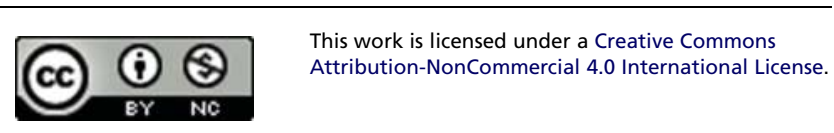


A given weight-adjusted dose suppressed the TSH below the lower reference limit $(<0.4 \mathrm{mU} / \mathrm{l})$ in a higher proportion of carcinoma patients, than it raised their $\mathrm{FT}_{3}$ level above the median level typical of the euthyroid controls ( $>5$ pmol/l) (Fig. 3A and B). Conversely, much lower doses reached a target of a fully suppressed TSH compared to the $\mathrm{FT}_{3}$ median (Fig. $3 \mathrm{~A}$ and $\mathrm{B}$ ). The same tendency is true for a more modest target below $1 \mathrm{mU} / \mathrm{l}$ for TSH in autoimmune thyroiditis or benign disease post surgery, although variation was higher in this panel (Fig. 3C and D). Overall, a significantly higher proportion of patients achieved TSH suppression compared to $\mathrm{FT}_{3}$ above median by Delong's test employing receiver operating characteristic curves $(P<0.001)$.

\section{Discussion}

In this cohort, dose requirements for $\mathrm{L}_{-} \mathrm{T}_{4}$-treated patients varied in a large euthyroid panel and were associated with many influences including gender, age, disease category and thyroid hormone conversion efficiency. However, not all of the treatment conditions necessarily aim at a biochemically euthyroid thyroid state as a comprehensive therapeutical goal, as defined by maintaining the respective reference ranges of all three parameters: $\mathrm{TSH}_{1} \mathrm{FT}_{4}$ and $\mathrm{FT}_{3}$. Particularly, in the treatment of thyroid carcinomas, for many patients in our sample the target was a lower or suppressed TSH below the reference range, which, as a consequence, raised $\mathrm{FT}_{4}$ levels above the upper reference range in a proportion of these patients. At both comparable levels of TSH suppression or similar $\mathrm{FT}_{3}$ concentrations, athyreotic thyroid carcinoma patients were taking a higher weight-adjusted dose of $\mathrm{L}_{-} \mathrm{T}_{4}$. Three remarkable and linked observations from this study were a dissociation between $\mathrm{FT}_{3}$ and $\mathrm{FT}_{4}$, an apparent disjoint between $\mathrm{TSH}$ and $\mathrm{FT}_{3}$ and an inverse association between $\mathrm{L}-\mathrm{T}_{4}$ dose and conversion efficiency.

The present study was a cross-sectional secondary analysis not involving a randomised design. As previously reported in a separate communication (22), the primary aim of this prospective observational study was to analyse further the interacting equilibria. While introducing some uncontrolled variations, this allowed for the study of a broader natural spectrum of responses, as observed in consecutive patients. $\mathrm{FT}_{3}$ or $\mathrm{FT}_{4}$ measurements were not compromised in any way by problematic conditions such as the non-thyroid illness syndrome, as the study was conducted in a cohort of otherwise 'healthy' out-patients without relevant comorbidity. There was no evidence for a potential bias stemming from a variable time interval
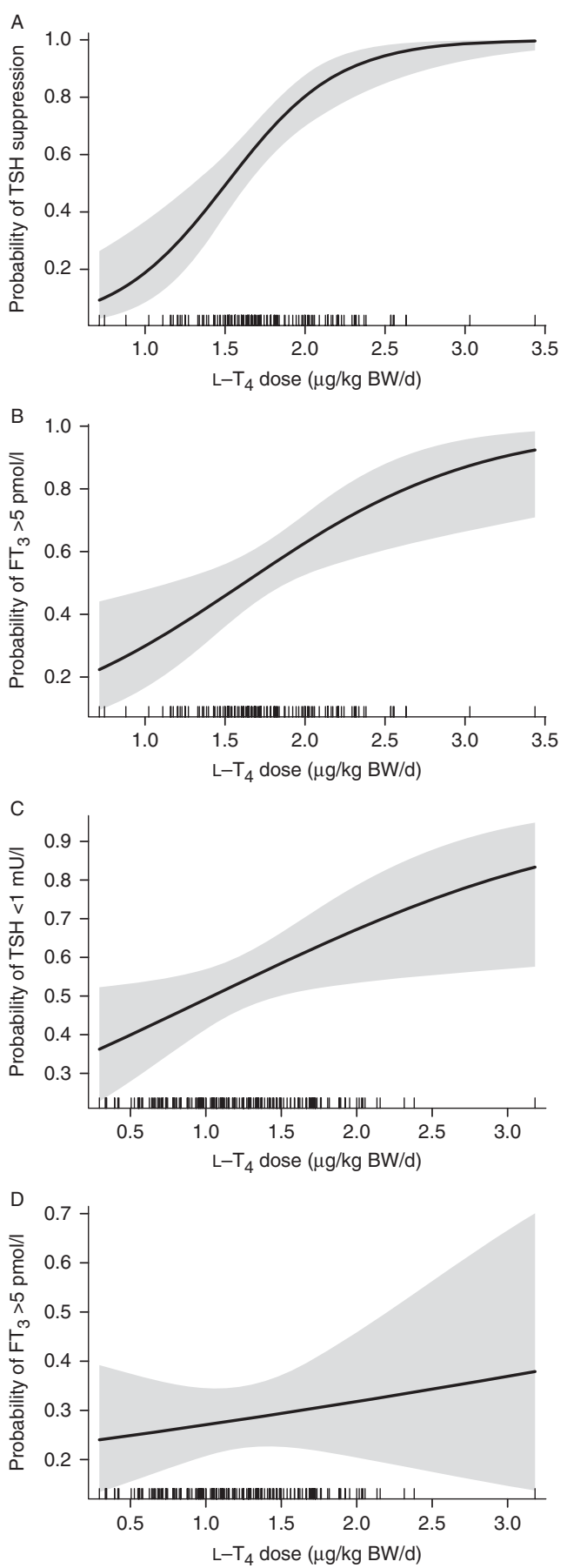

Figure 3

Probability plot of weight adjusted $\mathrm{L}-\mathrm{T}_{4}$ dose to (A) suppress TSH below its lower reference limit $(0.4 \mathrm{mU} / \mathrm{l})$ or $(\mathrm{B})$ raise $\mathrm{FT}_{3}$ above the median of euthyroid controls ( $>5 \mathrm{pmol} / \mathrm{l})$ in the carcinoma patients $(n=143)$, and $(\mathrm{C})$ suppress $\mathrm{TSH}<1 \mathrm{mU} / \mathrm{l}$ or (D) elevate $\mathrm{FT}_{3}$ above $5 \mathrm{pmol} / \mathrm{l}$ in benign disease (patients with autoimmune thyroiditis, $n=75$ and nodular thyroid disease post surgery, $n=111)$. Probability plots were created by logistic regression. The shaded areas indicate the confidence interval surrounding the fitted curve. The TSH targets were more frequently reached at a lower dose than the $\mathrm{FT}_{3}$ target (see Results).

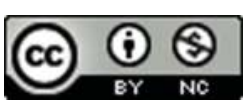


between $\mathrm{L}^{-\mathrm{T}_{4}}$ intake and blood sampling, which might result in an expected slight temporary elevation of circulating $\mathrm{FT}_{4}$ concentrations, as previously discussed (22). There were neither linear $(P=0.27)$ nor non-linear $(P=0.28)$ relationships with deiodinase activity.

In $\mathrm{L}_{-} \mathrm{T}_{4}$ treatment, equilibria typical of the healthy state were found not to be invariant, but profoundly altered (22). Here we disclose further consequences that are associated with alterations in the regulatory patterns in patients under $\mathrm{L}_{-} \mathrm{T}_{4}$ therapy. In particular, one aspect relates to the $\mathrm{L}_{-} \mathrm{T}_{4}$ dose and conversion efficiency. We estimated $T_{4}-T_{3}$ conversion by calculating the sum activity of peripheral deiodinases (see Subjects and methods). The measure is similar to the $\mathrm{FT}_{3}-\mathrm{FT}_{4}$ ratio, albeit more precise wherein it accounts for non-linear enzyme saturation kinetics. However, it does not further differentiate global activity by type of deiodinase. Thus, the source of $\mathrm{T}_{3}$ or contribution of various tissues to the $\mathrm{T}_{3}$ plasma pool cannot be discerned. We found that a poor converter status was associated with a higher $\mathrm{L}_{-} \mathrm{T}_{4}$ dose and higher serum $\mathrm{FT}_{4}$ levels but still lower absolute $\mathrm{FT}_{3}$ concentrations, compared to the more efficient converters. This paradoxically relates the higher $\mathrm{T}_{4}$ supply to a worsened rather than improved absolute $\mathrm{FT}_{3}$ level. This is not to say that an increasing dose will not raise on average the $\mathrm{FT}_{3}$ but that the dose response varies widely among individuals, and conversion inefficiency in some patients may outweigh the dose effect in terms of achievable absolute $\mathrm{FT}_{3}$ concentrations. How can this be explained? A high $\mathrm{L}_{-} \mathrm{T}_{4}$ dose may not invariably remedy $T_{3}$ deficiency owing to $T_{4}$-induced conversion inefficiency but could actually hinder its attainment through the inhibitory actions of the substrate itself and/or reverse $\mathrm{T}_{3}\left(\mathrm{rT}_{3}\right)$ on deiodinase type 2 activity (27). A study by Cettour-Rose et al. (28) confirmed that $\mathrm{rT}_{3}$, when infused into rats, inhibited deiodinase type 2 activity in the pituitary, cerebral cortex and brown adipose tissue, but interestingly, this did not have much impact on circulating $\mathrm{T}_{4}, \mathrm{~T}_{3}$ and TSH concentrations in the animals. However, in this model the $\mathrm{rT}_{3}$ effect was studied under rather artificial conditions in the absence of an abundant $\mathrm{T}_{4}$ supply with elevated $\mathrm{FT}_{4}$ levels that characterizes the treatment situation. In contrast, another recent experimental study has shown that escalating only the $\mathrm{L}^{-\mathrm{T}_{4}}$ dose fails to normalize serum $\mathrm{T}_{3}$ in the rat, and as a result, irrespective of local variations by type of deiodinase, all organs examined such as the brain, liver and skeletal muscle were hypothyroid at the tissue level in the presence of a normal serum TSH (29). This study suggests ubiquitination may be the limiting factor for $\mathrm{T}_{4}$ alone to restore true tissue euthyroidism in the rodent (29). The lack of TSH stimulation and absence or functional deficiency of the thyroid gland may also impair $\mathrm{T}_{4}-\mathrm{T}_{3}$ conversion (30). Another important consideration is that, just as $\mathrm{FT}_{4}$ and $\mathrm{FT}_{3}$ dissociate under $\mathrm{L}-\mathrm{T}_{4}$ therapy, so do $\mathrm{TSH}$ and $\mathrm{FT}_{3}$. While a high proportion of patients was able to achieve a target of a suppressed TSH below the lower reference limits or a TSH value $<1 \mathrm{mU} / 1$ in autoimmune thyroiditis, their $\mathrm{FT}_{3}$ levels at the same time frequently remained below the median $\mathrm{FT}_{3}$ level found in normal subjects. The situation differs from conditions in which $\mathrm{L}_{-} \mathrm{T}_{4}$ absorption may be impaired and, as a consequence, elevated TSH levels persist $(31,32,33)$. Thus, not even an $\mathrm{L}_{-} \mathrm{T}_{4}$ dose in which TSH is fully suppressed and $\mathrm{FT}_{4}$ by far exceeds its upper reference limit can guarantee above average $\mathrm{FT}_{3}$ levels in these patients, indicating an $\mathrm{FT}_{3}-\mathrm{TSH}$ disjoint. As a consequence, although dose escalation may help some patients who maintained a sufficiently efficient thyroid hormone conversion to raise their $\mathrm{FT}_{3}$ for euthyroidism and well-being, the strategy may not be invariably successful in all patients. In two studies, $\sim 15 \%$ of athyreotic patients could not even raise their $\mathrm{FT}_{3}$ above the lower reference limit on $\mathrm{L}_{4}(19,20)$. Another controlled follow-up study after hemithyroidectomy for benign euthyroid goitre suggests that this deficiency may have unwanted clinical consequences. In this study, weight gain after 2 years in association with a lowered thyroid function within the laboratory reference range was interpreted as a clinical manifestation of a permanently decreased metabolic rate (34).

$\mathrm{L}-\mathrm{T}_{4}$ dose requirements have been well studied and various regimes based on weight, BMI or more refined algorithms have been proposed to put patients on a presumed adequate dose from the very beginning $(10,11$, $12,13,14,15,16,35,36,37,38,39)$. As useful as these algorithms may be for average predictions and initial guidance in the general population, they do not take into account individual variations in the response to $\mathrm{L}_{-} \mathrm{T}_{4}$, such as conversion efficiency. Dosing strategies solely based on a TSH definition of euthyroidism neglect the important role of $\mathrm{FT}_{3}$, which has recently emerged as an equally significant parameter in defining thyroid physiology $(20,22,29,30,40,41)$. Central and peripheral regulatory mechanisms do not constitute divided levels of control, as has previously been assumed. Rather they are integrated via feed-forward control of deiodinase activity by TSH and operate jointly to maintain $\mathrm{T}_{3}$ homeostasis as an overarching goal (30).

\section{This work is licensed under a Creative Commons Attribution-NonCommercial 4.0 International License.}


While acknowledging the role of genetically determined differences in deiodinase activity affecting conversion rates, the poor converter status described here appears to emerge mainly as a consequence of the $\mathrm{T}_{4}$ monotherapy itself, induced by the mechanisms discussed above $(42,43,44,45)$. Compared to untreated subjects, deiodinase activity and conversion efficiency tend to be diminished in $\mathrm{L}^{\mathrm{T}} \mathrm{T}_{4}$ treatment $(20,22)$. However, individual pre-treatment measurements were not available for comparison. We found conversion inefficiency to be significantly correlated with low residual thyroid volume and most prevalent in athyreotic patients. However, differences in deiodinase activities were also apparent in the absence of a functioning thyroid gland within the group of thyroidectomised carcinoma patients. Overall, patients differ widely in the degree of the conversion impairment they suffer. This, in turn, may influence their dose requirements of $\mathrm{L}_{-} \mathrm{T}_{4}$ and, at a comparable weightadjusted $\mathrm{L}^{-\mathrm{T}_{4}}$ dose, their levels of TSH suppression and circulating $\mathrm{FT}_{3}$ concentrations.

We speculate that $\mathrm{L}_{-} \mathrm{T}_{4}$-induced conversion inefficiency could prevent some vulnerable subjects from reaching true tissue normality on $\mathrm{T}_{4}$ monotherapy alone. Those were not analysed separately in the numerous earlier $T_{3} / T_{4}$ trials and could be possible candidates for a combined $\mathrm{T}_{3} / \mathrm{T}_{4}$ treatment option, as recognized by some authors and the guidelines of the European Thyroid Association $(46,47)$. As a limitation, this study addresses biochemical treatment responses but did not evaluate patient-reported outcomes or biomarkers of thyroid hormone action.

Whether conversion efficiency and the resulting differences in relationships between $\mathrm{TSH}, \mathrm{FT}_{4}$ and $\mathrm{FT}_{3}$ are clinically useful markers of dosing inadequacy requires further well-designed prospective studies. Patient satisfaction, complaints and symptoms play an essential part in the clinical assessment. However, owing to considerable inter-individual variation, these measures apparently lack statistical power in a trial setting and have not been clearly linked to prognosis. For example, even a change in thyroid function as profound as the transition from the hypothyroid to the euthyroid state may be associated with only modest improvements in thyroid-related quality-of-life measures in patients with autoimmune thyroiditis (48). As a result, a trial size of several thousand subjects may be required to produce a credible result with adequate discriminatory power. Additionally, the exact outcome would depend on the overall makeup of the panel as regards the mixture of $\mathrm{T}_{4}-\mathrm{T}_{3}$ conversion capabilities. Possible long-term consequences of the observed biochemical alterations such as the altered $\mathrm{FT}_{3}-\mathrm{FT}_{4}$ ratio are also presently unknown.

The findings of the present study have several clinical implications. First, they recognize thyroid hormone conversion efficiency, as defined by the calculated global deiodinase activity or more simply the $\mathrm{T}_{3}-\mathrm{T}_{4}$ ratio, is an important determinant of $\mathrm{L}_{-} \mathrm{T}_{4}$ dose requirements and the biochemical response to treatment. Second, in view of a $\mathrm{T}_{4}$-related $\mathrm{FT}_{3}$ - $\mathrm{TSH}$ disjoint, $\mathrm{FT}_{3}$ measurement should be adopted as an additional treatment target. Third, in cases where an $\mathrm{FT}_{3}-\mathrm{FT}_{4}$ dissociation becomes increasingly apparent following dose escalation of $\mathrm{L}^{-\mathrm{T}_{4}}$, an alternate treatment modality, possibly $\mathrm{T}_{3} / \mathrm{T}_{4}$ combination therapy, should be considered, but further randomized controlled trials are required to assess the benefit versus risk in this particular group.

\section{Declaration of interest}

J W Dietrich is co-owner of the intellectual property rights for the patent 'System and Method for Deriving Parameters for Homeostatic Feedback Control of an Individual' (Singapore Institute for Clinical Sciences, Biomedical Sciences Institutes, Application Number 201208940e20120895). All other authors declare that there is no conflict of interest that could be perceived as prejudicing the impartiality of the research reported.

\section{Funding}

This research did not receive any specific grant from any funding agency in the public, commercial or not-for-profit sector.

\section{Acknowledgements}

The authors are grateful to Hans-Günther Wahl, Institute of Laboratory Medicine, Klinikum Lüdenscheid, for measuring thyroid hormones.

\section{References}

1 Bjoro T, Holmen J, Kruger O, Midthjell K, Hunstad K, Schreiner T, Sandnes L \& Brochmann H. Prevalence of thyroid disease, thyroid dysfunction and thyroid peroxidase antibodies in a large, unselected population. The Health Study of Nord-Trondelag (HUNT). European Journal of Endocrinology 2000143 639-647. (doi:10.1530/eje.0. 1430639)

2 Vanderpump MP, Tunbridge WM, French JM, Appleton D, Bates D, Clark F, Grimley Evans J, Hasan DM, Rodgers H \& Tunbridge F. The incidence of thyroid disorders in the community: a twenty-year followup of the Whickham Survey. Clinical Endocrinology 199543 55-68. (doi:10.1111/j.1365-2265.1995.tb01894.x)

3 Roberts CGP \& Ladenson PW. Hypothyroidism. Lancet 2004363 793-803. (doi:10.1016/S0140-6736(04)15696-1)

4 Mandel SJ, Brent GA \& Larsen PR. Levothyroxine therapy in patients with thyroid disease. Annals of Internal Medicine 1993119 492-502. (doi:10.7326/0003-4819-119-6-199309150-00009)

5 Biondi B \& Wartofsky L. Treatment with thyroid hormone. Endocrine Reviews 201435 433-512. (doi:10.1210/er.2013-1083) 
6 Bianco AC, Salvatore D, Gereben B, Berry MJ \& Larsen PR. Biochemistry, cellular and molecular biology, and physiological roles of the iodothyronine selenodeiodinases. Endocrine Reviews 200223 38-89. (doi:10.1210/edrv.23.1.0455)

7 Pilo A, Iervasi G, Vitek F, Ferdeghini M, Cazzuola F \& Bianchi R. Thyroidal and peripheral production of 3,5,3'-triiodothyronine in humans by multicompartmental analysis. American Journal of Physiology. Endocrinology and Metabolism 1990258 E715-E726.

8 Jonklaas J, Bianco AC, Bauer AJ, Burman KD, Cappola AR, Celi FS, Cooper DS, Kim BW, Peeters RP, Rosenthal MS et al. Guidelines for the treatment of hypothyroidism: prepared by the american thyroid association task force on thyroid hormone replacement. Thyroid 2014 24 1670-1751. (doi:10.1089/thy.2014.0028)

9 Baloch ZW, Carayon P, Conte-Devolx B, Demers LM, FeldtRasmussen U, Henry J-F, LiVosli VA, Niccoli-Sire P, John R, uf J et al. Laboratory medicine practice guidelines. Laboratory support for the diagnosis and monitoring of thyroid disease. Thyroid 200313 3-126. (doi:10.1089/105072503321086962)

10 Roos A, Linn-Rasker SP, van Domburg RT, Tijssen JP \& Berghout A. The starting dose of levothyroxine in primary hypothyroidism treatment: a prospective, randomized, double-blind trial. Archives of Internal Medicine 2005165 1714-1720. (doi:10.1001/archinte.165.15.1714)

11 Santini F, Pinchera A, Marsili A, Ceccarini G, Castagna MG, Valeriano R, Giannetti M, Taddei D, Centoni R, Scartabelli G et al. Lean body mass is a major determinant of levothyroxine dosage in the treatment of thyroid diseases. Journal of Clinical Endocrinology and Metabolism 2005 90 124-127. (doi:10.1210/jc.2004-1306)

12 Sukumar R, Agarwal A, Gupta S, Mishra A, Agarwal G, Verma AK \& Mishra SK. Prediction of $\mathrm{LT}_{4}$ replacement dose to achieve euthyroidism in subjects undergoing total thyroidectomy for benign thyroid disorders. World Journal of Surgery 201034 527-531. (doi:10.1007/ s00268-009-0345-3)

13 Mistry D, Atkin S, Atkinson H, Gunasekaran S, Sylvester D, Rigby AS \& England RJ. Predicting thyroxine requirements following total thyroidectomy. Clinical Endocrinology 201174 384-387. (doi:10.1111/ j.1365-2265.2010.03940.x)

14 Jin J, Allemang MT \& McHenry CR. Levothyroxine replacement dosage determination after thyroidectomy. American Journal of Surgery 2013 205 360-363 discussion 363-364. (doi:10.1016/j.amjsurg.2012.10.015)

15 Ojomo KA, Schneider DF, Reiher AE, Lai N, Schaefer S, Chen H \& Sippel RS. Using body mass index to predict optimal thyroid dosing after thyroidectomy. Journal of the American College of Surgeons 2013216 454-460. (doi:10.1016/j.jamcollsurg.2012.12.002)

16 Di Donna V, Santoro MG, de Waure C, Ricciato MP, Paragliola RM, Pontecorvi A \& Corsello SM. A new strategy to estimate levothyroxine requirement after total thyroidectomy for benign thyroid disease. Thyroid 201424 1759-1764. (doi:10.1089/thy.2014.0111)

17 Wiersinga WM. Paradigm shifts in thyroid hormone replacement therapies for hypothyroidism. Nature Reviews. Endocrinology 201410 164-174. (doi:10.1038/nrendo.2013.258)

18 Pepper GM \& Casanova-Romero PY. Conversion to Armour thyroid from levothyroxine improved patient satisfaction in the treatment of hypothyroidism. Journal of Endocrinology, Diabetes \& Obesity 20142 1055-1060.

19 Gullo D, Latina A, Frasca F, Le Moli R, Pellegriti G \& Vigneri R. Levothyroxine monotherapy cannot guarantee euthyroidism in all athyreotic patients. PLOS ONE 20116 e22552. (doi:10.1371/journal. pone.0022552)

20 Hoermann R, Midgley JEM, Larisch R \& Dietrich JW. Is pituitary TSH an adequate measure of thyroid hormone-controlled homoeostasis during thyroxine treatment? European Journal of Endocrinology 2013168 271-280. (doi:10.1530/EJE-12-0819)

21 Midgley JEM, Hoermann R, Larisch R \& Dietrich JW. Physiological states and functional relation between thyrotropin and free thyroxine in thyroid health and disease: in vivo and in silico data suggest a hierarchical model. Journal of Clinical Pathology 201366 335-342. (doi:10.1136/jclinpath-2012-201213)

22 Hoermann R, Midgley JEM, Giacobino A, Eckl WA, Wahl HG Dietrich JW \& Larisch R. Homeostatic equilibria between free thyroid hormones and pituitary thyrotropin are modulated by various influences including age, body mass index and treatment. Clinical Endocrinology 201481 907-915. (doi:10.1111/ cen.12527)

23 Larisch R, Giacobino A, Eckl W, Wahl HG, Midgley JEM \& Hoermann R. Reference range for thyrotropin. Post hoc assessment. Nuklearmedizin 201554 112-117. (doi:10.3413/Nukmed-0671-14-06)

24 Dietrich JW, Landgrafe G \& Fotiadou EH. TSH and thyrotropic agonists: key actors in thyroid homeostasis. Journal of Thyroid Research $2012 \mathbf{2 0 1 2}$ 1-29. (doi:10.1155/2012/351864)

25 Fellows I. Deducer: a data analysis GUI for R. Journal of Statistical Software 201249 1-15.

26 R Core Team. R: A Language and Environment for Statistical Computing. $R$ Foundation for Statistical Computing 2014. Vienna, Austria: R Foundation for Statistical Computing. (available at: http://www.R-project.org/)

27 Silva EJ, Gordon MB, Crantz FR, Leonard JL \& Larsen PR. Qualitative and quantitative differences in the pathways of extrathyroidal triiodothyronine generation between euthyroid and hypothyroid rats. Journal of Clinical Investigation 198473 898-907. (doi:10.1172/ JCI111313)

28 Cettour-Rose P, Visser TJ, Burger AG \& Rohner-Jeanrenaud F. Inhibition of pituitary type 2 deiodinase by reverse triiodothyronine does not alter thyroxine-induced inhibition of thyrotropin secretion in hypothyroid rats. European Journal of Endocrinology 2005153 429-434. (doi:10.1530/ eje.1.01984)

29 Werneck de Castro JP, Fonseca TL, Ueta CB, McAninch EA, Abdalla SM, Wittmann G, Lechan RM, Gereben B \& Bianco AC. Differences in hypothalamic type 2 deiodinase ubiquitination explain localized sensitivity to thyroxine. Journal of Clinical Investigation $2015 \mathbf{1 2 5}$ 769-781. (doi:10.1172/JCI77588)

30 Hoermann R, Midgley JEM, Larisch R \& Dietrich J. Integration of peripheral and glandular regulation of triiodothyronine production by thyrotropin in untreated and thyroxine-treated subjects. Hormone and Metabolic Research 201547 674-680. (doi:10.1055/s-0034-1398616)

31 Checchi S, Montanaro A, Pasqui L, Ciuoli C, De Palo V, Chiappetta MC $\&$ Pacini F. L-thyroxine requirement in patients with autoimmune hypothyroidism and parietal cell antibodies. Journal of Clinical Endocrinology and Metabolism 200893 465-469. (doi:10.1210/ jc.2007-1544)

32 Liwanpo L \& Hershman JM. Conditions and drugs interfering with thyroxine absorption. Best Practice \& Research. Clinical Endocrinology \& Metabolism 200923 781-792. (doi:10.1016/j.beem. 2009.06.006)

33 Robertson HMA, Narayanaswamy AKP, Pereira O, Copland SA, Herriot R, McKinlay AW, Bevan JS \& Abraham P. Factors contributing to high levothyroxine doses in primary hypothyroidism: an interventional audit of a large community database. Thyroid 201424 1765-1771. (doi:10.1089/thy.2013.0661)

34 Toft Kristensen T, Larsen J, Pedersen PL, Feldthusen A-D, Ellervik C, Jelstrup S \& Kvetny J. Weight gain and serum TSH increase within the reference range after hemithyroidectomy indicate lowered thyroid function. Journal of Thyroid Research 20142014 892573. (doi:10.1155/ 2014/892573)

35 Fish LH, Schwartz HL, Cavanaugh J, Steffes MW, Bantle JP \& Oppenheimer JH. Replacement dose, metabolism, and bioavailability of levothyroxine in the treatment of hypothyroidism. New England Journal of Medicine 1987316 764-770. (doi:10.1056/ NEJM198703263161302)

36 Banovac K, Carrington SA, Levis S, Fill MD \& Bilsker MS. Determination of replacement and suppressive doses of thyroxine. Journal of International Medical Research 199018 210-218. 
37 Gordon MB \& Gordon MS. Variations in adequate levothyroxine replacement therapy in patients with different causes of hypothyroidism. Endocrine Practice 19995 233-238. (doi:10.4158/EP.5.5.233)

38 Baehr KM, Lyden E, Treude K, Erickson J \& Goldner W. Levothyroxine dose following thyroidectomy is affected by more than just body weight. Laryngoscope 2012122 834-838. (doi:10.1002/lary.23186)

39 de Lima JG, de Mesquita DJTM, da Costa Fernandes F, de Souza ABC, Santos Juniordos AC, Reboucas B, de Lima NN, Sousa AGP \& Nobrega LHC. Comparison among the daily levothyroxine doses according to the etiology of hypothyroidism. Journal of Endocrinology and Metabolism 20133 1-6. (doi:10.4021/jem165w)

40 Abdalla SM \& Bianco AC. Defending plasma $T_{3}$ is a biological priority. Clinical Endocrinology 201481 633-641. (doi:10.1111/cen.12538)

41 Fonseca TL, Correa-Medina M, Campos MPO, Wittmann G, Werneck-de-Castro JP, Arrojo e Drigo R, Mora-Garzon M, Ueta CB, Caicedo A, Fekete $\mathrm{C}$ et al. Coordination of hypothalamic and pituitary $\mathrm{T}_{3}$ production regulates TSH expression. Journal of Clinical Investigation 2013123 1492-1500. (doi:10.1172/JCI61231)

42 Hoftijzer HC, Heemstra KA, Visser TJ, le Cessie S, Peeters RP, Corssmit EPM \& Smit JWA. The type 2 deiodinase ORFa-Gly3Asp polymorphism (rs12885300) influences the set point of the hypothalamus-pituitary-thyroid axis in patients treated for differentiated thyroid carcinoma. Journal of Clinical Endocrinology and Metabolism 2011 96 E1527-E1533. (doi:10.1210/jc.2011-0235)

43 Panicker V, Saravanan P, Vaidya B, Evans J, Hattersley AT, Frayling TM \& Dayan CM. Common variation in the DIO2 gene predicts baseline psychological well-being and response to combination thyroxine plus triiodothyronine therapy in hypothyroid patients. Journal of Clinical Endocrinology and Metabolism 200994 1623-1629. (doi:10.1210/ jc.2008-1301)

44 Taylor PN, Panicker V, Sayers A, Shields B, Iqbal A, Bremner AP, Beilby JP, Leedman PJ, Hattersley AT, Vaidya B et al. A meta-analysis of the associations between common variation in the PDE8B gene and thyroid hormone parameters, including assessment of longitudinal stability of associations over time and effect of thyroid hormone replacement. European Journal of Endocrinology 2011164 773-780. (doi:10.1530/EJE-10-0938)

45 McAninch EA, Jo S, Preite NZ, Farkas E, Mohácsik P, Fekete C, Egri P, Gereben B, Li Y, eng Y et al. Prevalent polymorphism in thyroid hormone-activating enzyme leaves a genetic fingerprint that underlies associated clinical syndromes. Journal of Clinical Endocrinology and Metabolism 2015100 920-933. (doi:10.1210/jc.2014-4092)

46 Wiersinga WM. Do we need still more trials on $\mathrm{T}_{4}$ and $\mathrm{T}_{3}$ combination therapy in hypothyroidism? European Journal of Endocrinology 2009161 955-959. (doi:10.1530/EJE-09-0879)

47 Wiersinga WM, Duntas L, Fadeyev V, Nygaard B \& Vanderpump MPJ. ETA guidelines: the use of $\mathrm{L}-\mathrm{T}_{4}+\mathrm{L}-\mathrm{T}_{3}$ in the treatment of hypothyroidism. European Thyroid Journal 20121 55-71. (doi:10.1159/000339444)

48 Watt T, Cramon P, Hegedüs L, Bjorner JB, Bonnema SJ, Rasmussen ÅK, Feldt-Rasmussen U \& Groenvold M. The thyroid-related quality of life measure ThyPRO has good responsiveness and ability to detect relevant treatment effects. Journal of Clinical Endocrinology and Metabolism 2014 99 3708-3717. (doi:10.1210/jc.2014-1322)

Received in final form 10 August 2015

Accepted 11 August 2015 http://www.endocrineconnections.org DOI: 10.1530/EC-15-0056
(C) 2015 The authors Published by Bioscientifica Ltd
This work is licensed under a Creative Commons Attribution-NonCommercial 4.0 International License. 